\title{
The Degree to Which Secondary School Teachers in Public Schools Accept the Use of Transformative Leadership by Their Principals from Their Perspective
}

\author{
Rahmeh Abbaas B. Alhameedyeen ${ }^{1}$ \\ Correspondence: Rahmeh Abbaas B. Alhameedyeen, Jordan. E-mail: rahma_daja@ymail.com \\ Received: April 18, 2018 \\ Accepted: May 2, 2018 \\ Online Published: May 10, 2018 \\ doi:10.5539/mas.v12n6p6 \\ URL: https://doi.org/10.5539/mas.v12n6p6
}

\begin{abstract}
The study aimed at identifying the degree to which secondary school teachers in public schools accept the use of transformative leadership by their principals from their perspective. The study used the descriptive method, and developed a questionnaire containing (20) paragraphs. The validity and reliability of the study tool has been verified. The study population contains the working teachers of high schools of the first semester of the academic year 2017-2018. They were taken among secondary public schools at Zarqa Education Principalate II. A random sample of 250 teachers was taken. The study concluded the following results:

- $\quad$ The mean averages and standard deviations showed that the degree to which secondary school teachers in public schools accept the use of transformative leadership by their principals from their perspective was moderate. Therefore, the study recommends that teachers be introduced to the importance of transformative leadership and give training courses to activate the application of transformative management in secondary public schools.

- $\quad$ There are statistically significant differences in the grades of study's sample of the degree to which secondary school teachers in public schools accept the use of transformative leadership by their principals from their perspective due to gender variable that was in favor of males. Therefore, the study recommends holding training courses for secondary school teachers to apply in their schools.

- $\quad$ There are statistically significant differences in the grades of study's sample of the degree to which secondary school teachers in public schools accept the use of transformative leadership by their principals from their perspective due to experience variable. Therefore, the study recommends that secondary school teachers in public schools should be informed of their experience from 1-10 years on this style of leadership.
\end{abstract}

Keywords: secondary school teachers, secondary grade, public schools, transformative leadership.

\section{Introduction}

\subsection{Introduce the Problem}

At present, the world is experiencing many and rapid changes that have spread to all country's sectors and institutions. It has become necessary to change in order to keep abreast of these developments. These institutions include educational institutions such as secondary public schools belonged to the Ministry of Education.

The school is a community institution that contributes to the preparation and education of students on religious values and established social customs. Secondary schools vary in their places and performance. The school is characterized by its effective leadership represented by the school principal. He is responsible for planning, organizing, evaluation, and follow-up. Further, he is held responsible for following up the development of education and teachers, as being resident educational supervisor, and active principal who invests material and human resources of the school, employs all the energies and creativity of teachers, and creates the human relations between them. He is the leader and they are teamwork (Duweik, 2005).

Leadership is one of the most important pillars of development and progress. It is "the ability to influence others" (Saud, 2013). Taking leadership will be voluntarily not forcedly. It is a collaborative process between the high school principal and the high school teachers. As the present time is featured with knowledge, technology and rapid changes, this matter requires reengineering the relationships between the school principal and the teachers in line with these changes. The secondary school administration faces many obstacles and problems need to be solved by the school principal and confronted in cooperation with teachers through the leadership style. It is the 
key for any school to make success as contributes to influence the teachers and create an atmosphere of respect, achievement and giving (Smeirat, Maqableh, 2014).

The leadership patterns of secondary school principals are varied. There is a democratic leadership based on human relations with principal, autocratic leadership that relies on central decision-making, command authority, noninterference leadership. It is the leadership that leaves responsibilities to teachers. The modern transformative leadership is based on links between the leader and the teamwork. This pattern is based on commitment, enthusiasm and motivation of teachers to change, positive thinking of future, participatory work, reconsider and satisfy, as much as possible, the needs satisfy of secondary teachers and provide them with enthusiasm and motivation towards school (Hor Thomas, 2009).

The transformative leadership benefits include increasing the motivation of secondary school teachers, improving their performance, and by which the principal can direct lower than them, and they participate more. This type of leadership is the most effective for the development, improvement and use of technology, and increases the ability of secondary school to be continuously improved by paying attention to the secondary school teachers by developing them professionally and academically, encouraging them to make additional efforts to achieve the goals of the secondary school. It also provides creative solutions to school problems, and there is a cooperative organizational environment that helps cooperation and participation, and can meet the requirements of the society (Seedawi, 2001).

Transformative leadership is characterized by stimulating and encouraging teachers to be empowered, delegated of authority, trust their ideas, and introduce new ideas that match knowledge and technology. It can also transform teachers from immobility to dynamism. It seeks to integrate the teacher into his school, collective cooperation between teachers and the school principal. The type of leadership is an incentive for achievement and selffulfillment for both high school principal and secondary school teachers (Ghamdi, 2013).

One of the school principal's traits, as transformative leader, is that he has a long-term vision of what the future school will be. He has the ability to communicate verbally and nonverbally; his energy is positive, his personality is attractive, he enjoys self-confidence, his activity is clear and prominent, he is interacting with teachers and is eager to achieve the goals and high productivity of the school. He can also employ all sources of the school to serve and promote the school. He seeks to make changes that are in line with technology and change (Abdel Aal, 2015).

The principal of the high school adopts several strategies in this type of leadership, such as visiting high school teachers within their classrooms, encouraging teachers to visit each other in classrooms, allowing them to experiment with new ideas, building school trust among all staff, and supporting voluntary initiatives, which will enhance the school and its progress towards development and progress. As well as professional development of teachers, renewing and improving their teaching competencies (Mutaman, 2003).

Transformative leadership in secondary school has many dimensions as ideal influencing. The school leader principal is an example for teachers in all easy, difficult and emergency situations. They show positive behaviors and extraordinary high morals, making teachers feel the need to do more, as well as inspiring motivation. The vision of secondary school's leader is clear, in which he is optimistic about the future and provides a measurable vision and application on the ground. This inspires the spirit of the teamwork (teachers of secondary stage), to be optimistic, active and serious at work. The school principal's intellectual stimulation is reflected in his ability to make the staff address the problems of the school and school daily course of action. He motivates them to search for creative and logical solutions that inspire creative and new ideas. There are individual considerations in which the school principal feels their needs and distributes their tasks by taking into account the individual differences between them based on their personal readiness (Ali, , 2015).

The goals of transformative leadership include developing teachers' ability to become leaders by encouraging them by the principal to be grown themselves, participated in decision-making, defined their roles, and to commit to school in order to achieve goals beyond their own, to reach the interests of their school. The leadership pattern followed by principal may reflected on their behavior in terms of acceptance of this leadership style (Naji, 2016)

It is noted that there is a lack of participation of teachers in school decisions, and school principals' unwillingness to involve teachers in school activities. Thus, few principals praise the good work of teachers for fear of being overwhelmed by teacher's superiority. Further, the majority of principals practice traditional school management; they take decisions unilaterally as well as resist changing and adhering to the laws and regulations literally. This study comes to know the degree to which secondary school teachers in public schools accept the use of transformative leadership by their principals from their perspective. 


\subsection{Problem of Study}

The problem of the study is to answer the following question:

What is the degree to which secondary school teachers in public schools accept the use of transformative leadership by their principals from their perspective?

\subsection{Explore Importance of the Problem}

It is hoped that the following entities will benefit from the results of this study:

- The Ministry of Education: through the effectiveness of this method in the school administration that to be applied in secondary public schools in the Ministry of Education in line with the technological developments taking place in the world at present.

- $\quad$ Researchers: by providing them with a conceptual framework on transformative leadership, and a study tool.

\subsection{Describe Relevant Scholarship}

Reference has been made to a number of previous Arab and foreign studies dealing with transformative leadership, which have been chronologically arranged from oldest to newest.

\subsubsection{Arabic Studies}

Ghamdi (2013) conducted a study entitled "Degree of Practice of Principals of Public Education Schools for Transformative Leadership in Al-Makhwa Governorate". The study aimed at defining the degree of practice of principals of public education schools practice for the transformative leadership in Makhwah governorate. The study used the surveying descriptive method. The questionnaire was the study's tool. The results showed that the degree of practice of principals of public education schools for the transformative leadership in Al-Makhwa Governorate were low. It further showed that there were statistically significant differences according to academic qualification variable in favor of bachelor's degree, specialization in favor of educational specialization, and years of experience for the benefit of 10 years and more.

Samiraat (2014) conducted a study entitled "The degree in which the secondary school principals practice a transformative leadership and its relation to teachers' motivation towards their work." The study aimed at revealing the degree in which the secondary school principals exercise the transformative leadership and their relation to teacher motivation towards their work. The results of the study showed that the degree in which the secondary school principals practice the transformative leadership and their relation to teachers' motivation towards their work was moderate, and that there were no statistically significant differences according to educational experience, gender, and scientific qualification variables in degree in which the secondary school principals practice the transformative leadership and their relation to teachers' motivation for their work.

Nahid, Ali (2015) conducted a study entitled "The role of transformative leadership in the organizational commitment of public secondary schools teachers in Jerash from their perspective". The study aimed at identifying the transformative leadership in the organizational commitment of the public secondary schools teachers in Jerash from their perspective. The questionnaire was the study tool. The results of the study showed that the transformative leadership practice's level of secondary school principals from perspective of teachers in Jerash governorate was medium average, and that there were statistically significant differences in the practicing level of principals of secondary schools in Jerash governorate according to gender, academic qualification, and experience variables. The study found that there were differences in the level of organizational commitment of teachers from their perspective depending on experience variable.

Khawla, Abdel-Aal (2015) conducted a study entitled "Availability degree of transformative leadership traits among secondary school principals in Gaza governorate and their relation to the level of professional affiliation of their teachers". The study aimed at identifying the traits of transformative leadership among secondary school principals in Gaza Governorate and their relation to the level of professional affiliation of their teachers. A questionnaire was the study tool. The results of the study showed that the availability degree of transformative leadership traits among secondary school principals in Gaza governorate was medium, and there were no statistically significant differences due to gender, academic qualification, and years of service's variables

Naji (2016) in her study entitled "Transformative Leadership in Secondary School Principals in Gaza Governorates in the Light of Islamic Educational Thought and its Means of Development" sought to define the degree of practice of secondary school principals in Gaza governorate for transformative leadership in the light of Islamic educational thought. The results of the study showed that the degree of the practice of secondary school principals in Gaza governorate for the transformative leadership in the light of the Islamic educational thought was medium, and there were statistically significance differences due to gender variable. And there were no statistically 
significant differences in the scores of the study's sample to the degree of secondary school principals in Gaza governorate for the transformative leadership in light of the Islamic educational thought attributed to academic qualification variable.

Qarawani, Khalid (2017) conducted a study entitled "The Role of Transformative Leadership in Male and Female Teachers in Palestine Schools". The study aimed at examining the role of transformative leadership in empowering male and female teachers in the schools of Palestine. The study used the descriptive approach, and the questionnaire was the tool of study. The results of the study showed that the role of transformational leadership in empowering male and female teachers in Palestine was high, and there were statistically significant differences according to gender variable in favor of females.

Intisar, Awawdeh (2017) conducted a study entitled "The Practicing Degree of Transformative Leadership in Classroom Management in Schools of Dura City from Perspective of Students of $10^{\text {th }}$ and $11^{\text {th }}$ Grades." The study aimed at defining the practicing degree of transformative leadership in classroom administration in Dura City. The results of the study showed that the practicing degree of transformative leadership in classroom administration in schools of Dura city from perspective of students of t0th and $11^{\text {th }}$ grades was medium, and found that there were statistically significant differences according to gender variable in favor of female students, and that there were no statistically significant differences depending on grade and branch variables.

\subsubsection{Foreign Studies}

Al-Raqqad, 2012, conducted a study entitled "Transformative Leadership of Academic Leaders and its Relation to Administrative Empowerment of Faculty Members in Jordanian Public Universities." The study aimed at examining the impact of transformative leadership of academic leaders and its relation to administrative empowerment of the faculty members working for Jordanian public universities. The results of the study showed that transformative leadership is highly applied in Jordanian public universities, and that there is a positive relationship between transformative leadership practices and the empowerment of faculty members.

Socorro (2013) conducted a study entitled "The Effects of Principals' Transformative Leadership Behaviors on Teacher Leadership Development and Teacher Self Efficacy."

The study aimed to understand the effects of transformative leadership behavior on teachers' leadership development from perspective of teachers. The descriptive approach was used in the study. The results of the study showed that the behavior of principals' transformative leadership was significant and that there were no statistically significant differences according to school grade (primary and secondary).

(Sha, 2014), at her study entitled "Empowering English Teachers Through Distributed Leadership: a critical perspective on leadership practices in an educational institutions. from Their Perspective", aimed at empowering English language teachers through distributed leadership. The study used semi-formal interview as a tool for study, in addition to qualitative approach. The results of the study showed that teachers suffer from the structure of organization, and non-empowerment.

Raman, Huey, Yahya, Yaacub, \& Rozalinda, 2015) conducted a study entitled "Relationship Between Principals' Transformative Leadership Style and Secondary School Teachers Commitment." The study aimed at determining the relationship between principals' transformative leadership style secondary school teachers' commitment in Malaysia. They used analytical descriptive approach. The questionnaire was the study tool. The results of the study showed that there is no difference between the level of education and the level of school principals who follow the transformative leadership style. Further, the results showed that there in a relation between the transformative leadership's style and the teachers' commitment.

\subsubsection{Location of Current Study among Previous Ones}

Arab and foreign studies were used in terms of theoretical literature, the tool used, and the choice of the study method, such as studies of Samiraat, Maqableh (2014), Abdel-Aal (2015), a\& Naji (2016). These studies focused on transformative leadership and its traits, and how can be used by principals. It linked it to important administrative topics such as job satisfaction and managerial empowerment. What distinguishes this study from previous studies is that it dealt with a new topic and it accepts secondary school teachers in public schools to use their leadership transformative leadership from their perspective, which had been not discussed by any previous study according to my knowledge and belief.

\subsection{Objective and Question of the Study}

The study aimed to determine the degree to which secondary school teachers in public schools accept the use of transformative leadership by their principals from their perspective. To achieve this goal, the study's questions will 
be answered:

Question 1: What is the degree to which secondary school teachers in public schools accept the use of transformative leadership by their principals from their perspective?

Question 2: Are there statistically significant differences at level of $(\mathrm{p}=0.05)$ in the sample of the degree to which secondary school teachers in public schools accept the use of transformative leadership by their principals from their perspective due to gender variables, specialization and teaching experience?

\subsubsection{Definitions:}

"Secondary school teachers": Those who work in teaching for educational institutions, and teach $11^{\text {th }}$ and $12^{\text {th }}$ grades for students between $(17 \& 18)$ years old.

"Secondary stage": Procedurally: It is one of the stages in general education system in the Hashemite Kingdom of Jordan, which includes the $11^{\text {th }}$ and $12^{\text {th }}$ grades for students between $17 \& 18$ years old (Nahed, 2015).

"Public Schools": Schools belonged to Jordan Ministry of Education.

"Transformative leadership": is one of the modern patterns of leadership, through which the leader and teamwork eager to elevate each other to the highest levels of motivation (Abdel Aal, 2015).

It is defined by Ghamdi (2013) as "providing technical, managerial, and behavioral skills to use resources and make use of them in the least time, effort and cost."

Procedurally: recognition of secondary school teachers in the role of school principal to express their wishes, hopes, ambitions, and gaining their cooperation to reach the secondary public school to excellence, development and progress by keeping pace with rapid technological changes.

\subsubsection{Study Limitions}

Following are the study limitations:

"Human Beings": Teachers of secondary public schools in Zarqa Education Governorate II.

"Time": The study was limited to teachers of secondary public schools in Zarqa Education Governorate II for the academic year 2010-2017

"Place": Secondary public schools in Zarqa Education Governorate II.

\section{Method}

The study followed the descriptive surveying approach as the most suitable for such studies.

\subsection{Study Population}

The study population is composed of all male and female teachers who teach secondary grades in the public schools of Zarqa Education Directorate II, in the second semester of the academic year 2017-2018. They were (500) male and female teachers and teachers, selected from secondary public schools in Zarqa Education Directorate II, according to statistics of the Ministry of Education for the year $2017-2018$

\subsection{Sampling Procedures}

\subsubsection{Sample Distribution:}

A random sample, consisting of (250) male and female teachers, was taken as shown in the following table:

Table (1). Sample distribution by gender, specialization and experience

\begin{tabular}{cccccc}
\hline Gender & Specialization & \multicolumn{2}{c}{ Human sciences } & \multicolumn{2}{c}{ Experience } \\
\hline Gender & Experience & Frequency & Ratio \% & Frequency & Ratio \% \\
& From 1 to 5 & 7 & $2.8 \%$ & 14 & $5.6 \%$ \\
Males & From 6 to 10 & 16 & $6.4 \%$ & 32 & $12.8 \%$ \\
& More than 1 1 & 13 & $5.2 \%$ & 18 & $7.2 \%$ \\
& From 1 to 5 & 23 & $9.2 \%$ & 18 & $7.2 \%$ \\
Females & From 6 to 10 & 30 & $12.0 \%$ & 57 & $22.8 \%$ \\
& More than 1 1 & 10 & $4.0 \%$ & 12 & $4.8 \%$ \\
& Total & $\mathbf{9 9}$ & $\mathbf{3 9 . 6 \%}$ & $\mathbf{1 5 1}$ & $\mathbf{6 0 . 4 \%}$ \\
\hline
\end{tabular}

\subsubsection{Study Tool}

The study aimed at defining the degree to which the secondary grades' teachers in public schools accept the use of 
transformative leadership by their principals from their perspective. To achieve the objective of the study and answer their questions, the theoretical literature related to the subject matter of study and related previous studies were reviewed, such as Ghamdi (2013), Ali (2015), and Awawdah (2017). A questionnaire was developed consisting of (20) paragraphs. Lycert was used as follows: high, medium, and low degrees.

2.2.3 Tool Validity

The questionnaire was presented to ten arbitrators working at educational administration and jurisprudence to check the tool in terms of construction, language, integrity and clarity.

\subsubsection{Tool Reliability}

To check reliability of the questionnaire, Cronbach's Alpha is calculated to be (0.904) for the questionnaire questions.

\subsubsection{Tool Variables}

The study included the following variables:

Independent: the reality of transformative leadership

Dependent: The degree to which the teachers of secondary stage accept the use of transformative leadership.

Moderating:

- $\quad$ Gender: Male, and female.

- Specialization: Scientific and humanitarian disciplines.

- $\quad$ Experience: From (1-5 years), from (6-10 years), (more than 11).

\subsubsection{Statistical Processing Methods}

To reach the study's objectives, the Statistical Package for Social Sciences (SPSS) was used to analyze data and obtain the results as follows:

- Frequencies and percentages to describe the characteristics of the study sample.

- Mean averages and standard deviations to identify the responses of the sample members on each of questionnaire's paragraphs.

- Cronbach's Alpha to verify the reliability of questionnaire.

- T-test for independent samples to find out significant differences between two independent groups.

- One-way ANOVA analysis to define the significant differences between more than two independent groups.

- The following scaling was used to indicate the mean responses of the sample respondents:

High approval (2.34 and above), medium approval (1.67 to less than 2.34), and low approval (less than 1.67).

\section{Results}

Following are the results of the study:

\subsection{Results Related to Question I}

What is the degree to which secondary school teachers in public schools accept the use of transformative leadership from their perspective?

To answer this question, the mean averages, standard deviations, and degrees' ordering of secondary teachers at public schools to accept the use of transformative leadership by their principals were calculated. The results were as follows:

Table (2). Mean averages, standard deviations and degrees' ordering of Secondary school teachers at public schools to accept the use of transformative leadership by their principals

\begin{tabular}{|c|c|c|c|c|c|}
\hline No. & Paragraph & $\begin{array}{c}\text { Mean } \\
\text { Average }\end{array}$ & $\begin{array}{l}\text { Standard } \\
\text { deviation }\end{array}$ & $\begin{array}{l}\text { Acceptance } \\
\text { Degree }\end{array}$ & Order \\
\hline 7 & Clear activity while performing his duties & 2.40 & 0.739 & High & 1 \\
\hline 8 & $\begin{array}{l}\text { Encourage the building of positive relationships } \\
\text { between teachers }\end{array}$ & 2.38 & 0.809 & High & 2 \\
\hline 1 & $\begin{array}{l}\text { Sharing with teachers in developing the vision, mission } \\
\text { and goals of the school }\end{array}$ & 2.24 & 0.811 & Medium & 3 \\
\hline
\end{tabular}




\begin{tabular}{|c|c|c|c|c|c|}
\hline No. & Paragraph & $\begin{array}{c}\text { Mean } \\
\text { Average }\end{array}$ & $\begin{array}{r}\text { Standard } \\
\text { deviation }\end{array}$ & $\begin{array}{l}\text { Acceptance } \\
\text { Degree }\end{array}$ & Order \\
\hline 9 & Follow-up professional growth of teachers & 2.15 & 0.802 & Medium & 4 \\
\hline 6 & Flexibility in practicing leadership & 2.11 & 0.799 & Medium & 5 \\
\hline 18 & Provide teachers with a positive vision for the future & 2.10 & 0.835 & Medium & 6 \\
\hline 3 & $\begin{array}{l}\text { Collaborate with teachers to solve the problems they } \\
\text { face }\end{array}$ & 2.09 & 0.814 & Medium & 7 \\
\hline 5 & Trust in teachers & 2.09 & 0.819 & Medium & 8 \\
\hline 13 & Stimulate constructive competition between teachers & 2.09 & 0.804 & Medium & 9 \\
\hline 16 & $\begin{array}{l}\text { Strengthening the role of community in the development } \\
\text { of school }\end{array}$ & 2.08 & 0.822 & Medium & 10 \\
\hline 20 & Stimulating teachers towards change & 2.08 & 0.803 & Medium & 11 \\
\hline 17 & Use delegation authority method & 2.07 & 0.791 & Medium & 12 \\
\hline 2 & Pay attention to meet the desires of teachers & 2.06 & 0.773 & Medium & 13 \\
\hline 4 & Building a solid value system & 2.05 & 0.807 & Medium & 14 \\
\hline 19 & Encourage teacher empowerment & 2.05 & 0.815 & Medium & 15 \\
\hline 14 & $\begin{array}{l}\text { Motivation for professional and academic achievement } \\
\text { of teachers }\end{array}$ & 2.04 & 0.813 & Medium & 16 \\
\hline 11 & Encouraging participation in seminars and conferences & 2.02 & 0.799 & Medium & 17 \\
\hline 12 & Eager to develop teachers' creativity & 2.00 & 0.804 & Medium & 18 \\
\hline 15 & Eager to update teaching competencies of teachers & 1.96 & 0.818 & Medium & 19 \\
\hline \multirow[t]{2}{*}{10} & Sharing teachers in decisions related to school & 1.59 & 0.636 & Low & 20 \\
\hline & General average & 2.08 & 0.474 & Medium & \\
\hline
\end{tabular}

The table above shows that the mean averages for grades of secondary school teachers at public schools to accept the use of transformative leadership by their principals ranged between $1.59-2.40$. Paragraphs (7) and (8) obtained high acceptance grades as (7) "Clear activity while performing his duties" was high by (2.40), while the rest of paragraphs were medium, except for paragraph (10) (Sharing teachers in decisions related to school) that obtained the lowest mean average by (1.59).

The table also shows that the total number of paragraphs scored a mean average by (2.08) with medium acceptance degree. This means that the degree of secondary school teachers at public schools to accept the use of transformative leadership by their principals was medium. This result was in line with the studies of Smeerat, Maqableh (2014), Ali, (2015), Naji, (2016), and Awawdeh (2017), but disagreed with the studies of Raqqad (2012), and Qarawani (2017).

\subsection{Results Related to Question II}

Are there statistically significant differences at level of $(\mathrm{p}=0.05)$ in sample's grades in relevant to the degree to which the secondary teachers at public schools accept the use of transformative leadership by their principals from their perspective due to gender, specialization and teaching experience variables.

\subsubsection{According to Gender}

To answer this question, the mean averages and standard deviations were calculated for the sample of study with respect to the degree to which the secondary teachers at public schools accept the use of transformative leadership by their principals from their perspective according to gender variable, and T-test was used to find out the differences significance between these averages as shown in the following table:

Table (3). Results of T-test for independent samples to find out significant differences in the study's sample with respect to the degree to which the secondary school teachers accept the use of transformative leadership by their leadership from their perspective depending on gender variable

\begin{tabular}{ccccccc}
\hline Gender & No. & $\begin{array}{c}\text { Mean } \\
\text { Average }\end{array}$ & $\begin{array}{c}\text { Standard } \\
\text { deviation }\end{array}$ & "T" Value & $\begin{array}{c}\text { Freedom } \\
\text { Degree }\end{array}$ & Significance Level \\
\hline Males & 100 & 2.16 & 0.448 & 2.251 & 248 & 0.025 \\
Females & 150 & 2.03 & 0.484 & & & \\
\hline
\end{tabular}

The table above shows that there are statistically significant differences at a level of less than (0.05) in grades of study's sample with respect to the degree to which the secondary teachers at public schools accept the use of transformative leadership by their principals from their perspective due gender variable. This means that the 
secondary school female teachers at public schools accept the use of transformative leadership their leadership more than male teachers.

\subsubsection{According to Specialization}

To answer this question, the mean averages and standard deviations were calculated for the sample of study with respect to the degree to which the secondary teachers at public schools accept the use of transformative leadership by their principals from their perspective according to specialization variable, and T-test was used to find out the differences significance between these averages as shown in the following table:

Table (4). Results of T-test for independent samples to find out significant differences in the study's sample with respect to the degree to which the secondary school teachers accept the use of transformative leadership by their leadership from their perspective depending on specialization variable

\begin{tabular}{ccccccc}
\hline Gender & No. & $\begin{array}{c}\text { Mean } \\
\text { Average }\end{array}$ & $\begin{array}{c}\text { Standard } \\
\text { deviation }\end{array}$ & "T" Value & $\begin{array}{c}\text { Freedom } \\
\text { Degree }\end{array}$ & $\begin{array}{c}\text { Significance } \\
\text { Level }\end{array}$ \\
\hline Scientific & 151 & 2.08 & 0.416 & 0.062 & 248 & 0.951 \\
Humanity & 99 & 2.08 & 0.552 & & & \\
\hline
\end{tabular}

The table above shows that there are no statistically significant differences at a level of less than (0.05) in grades of study's sample with respect to the degree to which the secondary teachers at public schools accept the use of transformative leadership by their principals from their perspective due specialization variable. This means that degree to which the secondary school female teachers at public schools accept the use of transformative leadership their leadership is similar regardless their specialization.

\subsubsection{According to Teaching Experience}

To answer this question, the mean averages and standard deviations were calculated for the sample of study with respect to the degree to which the secondary teachers at public schools accept the use of transformative leadership by their principals from their perspective according to experience variable as shown in the following table:

Table (5). Mean averages, standard deviations of grades of study's sample with respect to the degree to which the secondary school teachers at public schools accept the use of transformative leadership by their principals from their perspective depending on experience variable

\begin{tabular}{cccc}
\hline Years of Experience & No. & Mean Average & Standard deviation \\
\hline From 1 - 5 & 62 & 1.95 & 0.599 \\
From 6 - 10 & 135 & 2.08 & 0.291 \\
More than 11 & 53 & 2.23 & 0.626 \\
\hline
\end{tabular}

In order to know the significance of these differences, one-way analysis of variance (ANOVA) was performed. The results were as follows:

Table (6). One-way analysis of variance (ANOVA) to find out the significance of differences in the sample of study with respect to the degree to which the secondary school teachers at public schools accept the use of transformative leadership by their principals from their perspective depending on experience variable

\begin{tabular}{llllll}
\hline \multicolumn{1}{c}{ Variance source } & Total squares & $\begin{array}{c}\text { Freedom } \\
\text { Degrees }\end{array}$ & $\begin{array}{c}\text { Average } \\
\text { squares }\end{array}$ & (P) Value & $\begin{array}{c}\text { Significance } \\
\text { Level }\end{array}$ \\
\hline Between groups & 2.254 & 2 & 1.127 & 5.195 & 0.006 \\
Within groups & 53.597 & 247 & 0.217 & & \\
Total & 55.852 & 249 & & & \\
\hline
\end{tabular}

The table above shows that there are statistically significant differences at a level of less than (0.05) in grades of study's sample with respect to the degree to which the secondary teachers at public schools accept the use of transformative leadership by their principals from their perspective due experience variable, and to find out which experience categories can make these differences then make LSD) test for comparison. The results were as follows: 
Table (7). Test results (LSD) to compare sample study estimates to the degree of acceptance of teachers The secondary stage of their principals use transformative leadership from their perspective depending on the variable of experience

\begin{tabular}{lccc}
\hline \multicolumn{1}{c}{ Experience } & Mean Average & From 6 - 10 & More than 11 \\
\hline From 1 - 5 & 1.95 & & $*$ \\
From 6 - 10 & 2.08 & & $*$ \\
More than 11 & 2.23 & $*$ & \\
\hline
\end{tabular}

* Statistically significant

The table above shows that there are statistically significant differences at level of $(0.05)$ in the estimation of study's sample with respect to the degree to which the secondary teachers at public schools accept the use of transformative leadership by their principals from their perspective with experience from (1-5), (more than 11), to favor of those having experience (more than 11 years), and between (6-10) and (more than 11 years) to favor of those having experience (more than 11 years). This means that the degree to which the secondary school teachers with (11 years) experience at public schools accept the use of transformative leadership by their principals was more than those having less experience.

\section{Discussion}

\subsection{Discussion of the results in connection with Question I}

What is the degree to which the secondary school teachers in public schools accept the use of transformative leadership from their perspective?

Table (2) above shows that the mean averages for grades of secondary school teachers at public schools to accept the use of transformative leadership by their principals ranged between $1.59-2.40$. Paragraphs (7) and (8) obtained high acceptance grades as (7) "Clear activity while performing his duties" was high by (2.40), while the rest of paragraphs were medium, except for paragraph (10) (Sharing teachers in decisions related to school) that obtained the lowest mean average by (1.59).

The table also shows that the total number of paragraphs scored a mean average by (2.08) with medium acceptance degree. This means that the degree of secondary school teachers at public schools to accept the use of transformative leadership by their principals was medium. This result was in line with the studies of Smeerat, Maqableh (2014), Ali, (2015), Naji, (2016), and Awawdeh (2017), but disagreed with the studies of Raqqad (2012), and Qarawani (2017).

The table also shows that the total number of paragraphs reached an average of 2.08 and the average approval score. This indicates that the acceptance of secondary school teachers in public schools for the use of their principals was moderately driving. (2016), and the study of Alawawdah (2017). The results differed with the study of AL-Raqqad (2012) and the Qarawani study (2017).

This result is due to the fact that the successful school's principal leaves no stone unturned, who employs his expertise in applying the modern principles of management. He is also required to carry out many administrative, leadership and technical tasks and functions. He is also evaluated by the Director of Education. He is the leader in his school, and expected to be an exemplary for teachers in vigor, activity and excellence, and oversees all the affairs of the school and facilities, and facilitates it to be best used.

With regard to paragraph that received the lowest average arithmetic, it may be attributed to the fact that some principals resort to erroneous educational practices in terms of adhering to the rules of law and their application as they are, away from the spirit of law. As well as taking decision unilaterally without consulting and sharing teachers thereof as believes that that educational system allowed him to do so, away from the partnership and cooperation with them, which makes the productive efficiency and giving by teachers is low and their level of performance and satisfaction at the lowest levels.

Positive relationships between teachers have the greatest role in achieving positive results for the educational process, achieving the goals of the school, as well as raising the morale of the teachers, prevalence of democracy, loyal to position, giving, and accept with pleasure.

\subsection{Discussion of the results regarding Question II}

Are there statistically significant differences at level of $(\mathrm{p}=0.05)$ in sample's grades in relevant to the degree to which the secondary teachers at public schools accept the use of transformative leadership by their principals from 
their perspective due to gender, specialization and teaching experience variables.

\subsubsection{According to Gender}

The table above shows that there are statistically significant differences at a level of less than $(0.05)$ in grades of study's sample with respect to the degree to which the secondary teachers at public schools accept the use of transformative leadership by their principals from their perspective due gender variable. This means that the secondary school female teachers at public schools accept the use of transformative leadership their leadership more than male teachers.

This result is due to the fact that male teachers sometimes refuse to obey their principals' orders. They also reject driven-management, not the leadership of principal, as well as responsibilities placed on them outside the school walls, which makes their thinking about how to manage their family matters more important. On the other hand, the female teachers accept respectfully and willingly the transformative administration, accept the school work voluntarily to the school laws and organizational commitment; they do their school duties professionally more than others. The result was similar with the study of Ali (2015), Qarwani (2017), but the results differed with the study of (Socorro, 2013), (Sameerat \& Maqableh 2014), (Al-Aala, 2015) and (Naji, 2016).

\subsubsection{According to Specialization}

Table (4) above shows that there are no statistically significant differences at a level of less than (0.05) in grades of study's sample with respect to the degree to which the secondary teachers at public schools accept the use of transformative leadership by their principals from their perspective due specialization variable. This means that degree to which the secondary school female teachers at public schools accept the use of transformative leadership their leadership is similar regardless their specialization.

This result is attributable to that the secondary teachers with different disciplines accept their principals to practice transformative leadership. The school environments are similar with same educational system and only belonged to the Ministry of Education. This result was agreed with the study of (Socorro, 2013) (2017), (Awawdeh, 2017), but disagreed with the study of (Ghamdi, 2013).

\subsubsection{According to Experience}

Table (6) above shows that there are statistically significant differences at level of $(0.05)$ in the grades of study's sample with respect to the degree to which the secondary teachers at public schools accept the use of transformative leadership by their principals from their perspective due to experience variable. Table (7) above shows that there are statistically significant differences at level of $(0.05)$ in the estimation of study's sample with respect to the degree to which the secondary teachers at public schools accept the use of transformative leadership by their principals from their perspective with experience from (1-5), (more than 11), to favor of those having experience (more than 11 years), and between (6-10) and (more than 11 years) to favor of those having experience (more than 11 years). This means that the degree to which the secondary school teachers with (11 years) experience at public schools accept the use of transformative leadership by their principals was more than those having less experience.

This result is attributable to that the experienced teachers (11 years and over) acquired experience in life, in teaching, and their experiments are many and varied. They know how things are going and business. They are familiar with all subjects, had attended many training courses, they are always familiar with all school developments, had worked with more than one principals that benefited from their experience. This result was consistent with the study of (Ghamdi, 2013), and differed with study of (Smirat, Maqableh, 2014) and (Abdel-Al, 2015).

\subsection{Recommendations}

Based on the findings of the study, the study recommends the following:

1) Mean averages and standard deviations showed that the degree to which the secondary teachers at public schools accept the use of transformative leadership by their principals was medium. Therefore, the study recommends that teachers be informed about the importance of transformative leadership and the provision of training courses to activate the application of transformative management in secondary public schools.

2) There were statistically significant differences in the grades of study's sample with respect to the degree to which the secondary teachers at public schools accept the use of transformative leadership by their principals from their perspective according gender variable. It was in favor of males. Therefore, the study recommends holding training courses for secondary teachers to be applied in their schools.

3) There were statistically significant differences in the grades of study's sample with respect to the degree to which the secondary teachers at public schools accept the use of transformative leadership by their principals 
from their perspective according experience variable. Therefore, the study recommends that secondary teachers must be learned that their experiences are different (1-10) on such pattern of leadership.

\section{References}

Abdel Aal, K. (2015). Availability degree of transformative leadership traits of secondary school principals in Gaza Governorate and their relation to the level of professional affiliation of their teachers. Unpublished Master Thesis, Islamic University, Gaza, Palestine.

Ali, Nahed (2015). Role of transformative leadership in organizational commitment of secondary school teachers in Jerash from their perspective. Unpublished Master Thesis, Jerash University, Jerash, Jordan.

Awawdah, I. (2017). Practicing degree of transformative leadership in classroom management in schools of Dura City from perspective of $10^{\text {th }}$ and $11^{\text {th }}$ grades' students. Al-Quds Journal of Open University for Educational and Psychological Studies, 6(20), 63-75.

Dweik, T. (2005). Effective school management, its components \& Prospects. Amman: Dar Juhayna.

Ghamdi, J. (2013). Practice of Transformative Leadership by Principals of General Education Schools in Makhwah Governorate. Unpublished Master Thesis, Middle East University, Amman, Jordan.

Hor, T. (2009). The art of school leadership. Translated by Walid Ezzat. Riyadh: Obeikan.

Mutman, M. (2003). Preparation of School Principal to Lead Change: A Leadership Approach for Effective Coexistence in the 21st Century. Amman: Academic Book Center.

Naji, N. (2016). Transformative leadership among secondary school principals in Gaza governorates in the light of Islamic educational thought and ways of developing it. Unpublished MA, Islamic University, Gaza, Palestine.

Qarwani, K. (2017). The role of transformative leadership in empowering male teachers and female in Palestine's schools. Journal of Faculty of Education in Assiut Egypt, 2(33), 299-356.

Sameerat, S., \& Maqableh, A. (2014). The Practicing Degree of Secondary Principals for Transformative Leadership and its Relation to Teachers' motivation towards their work. Journal of Educational Sciences Studies, 1(41), 33-63.

Saudi, R. (2013). Educational Leadership: Concepts and Prospects. Amman: Wael House.

Sidawi, A. (2001). Educational Transformative Leadership: Educational Administration in Arab Countries. Beirut: Lebanese Commission for Educational Sciences.

\section{Foreign References}

Raman, A., Chuey, D., Daud, Y., \& Khaled R. (2015). Relationship Between Principals Transformative Leadership Style and Secondary School Teachers Commitment. Asian Social, 11(15), 155-1170.

Raqqad, H. (2012). Transformative Leadership of Academic Leaders official Jordanian Universities and Its Relation with Teaching Staff Empowerment. Al- Najah University Journal for Research Humanities, 26(5), 125-140.

Shah, s. (2014). Empowering English teachers through distributed leadership: a critical perspective on leadership practices in an educational institutions. International Journal of Business and Social Science, 5(10), 220-224.

Socorro, E. (2013). The Effects of Principals Transformative Leadership Behaviors on Teacher Leadership Development and Teacher Self Efficacy. The University of Texas Pan American.USA.

\section{Copyrights}

Copyright for this article is retained by the author(s), with first publication rights granted to the journal.

This is an open-access article distributed under the terms and conditions of the Creative Commons Attribution license (http://creativecommons.org/licenses/by/4.0/). 